July 2006

\title{
Rho kinase as a novel molecular therapeutic target for hypertensive internal anal sphincter
}

\author{
Satish Rattan \\ Thomas Jefferson University \\ Marcio A.F. De Godoy \\ Thomas Jefferson University \\ Chirag A. Patel \\ Thomas Jefferson University
}

Follow this and additional works at: https://jdc.jefferson.edu/medfp

Part of the Medical Genetics Commons

Let us know how access to this document benefits you

\section{Recommended Citation}

Rattan, Satish; De Godoy, Marcio A.F.; and Patel, Chirag A., "Rho kinase as a novel molecular therapeutic target for hypertensive internal anal sphincter" (2006). Department of Medicine Faculty Papers. Paper 17.

https://jdc.jefferson.edu/medfp/17

This Article is brought to you for free and open access by the Jefferson Digital Commons. The Jefferson Digital Commons is a service of Thomas Jefferson University's Center for Teaching and Learning (CTL). The Commons is a showcase for Jefferson books and journals, peer-reviewed scholarly publications, unique historical collections from the University archives, and teaching tools. The Jefferson Digital Commons allows researchers and interested readers anywhere in the world to learn about and keep up to date with Jefferson scholarship. This article has been accepted for inclusion in Department of Medicine Faculty Papers by an authorized administrator of the Jefferson Digital Commons. For more information, please contact: JeffersonDigitalCommons@jefferson.edu. 


\title{
Rho Kinase as a Novel Molecular Therapeutic Target for Hypertensive Internal Anal Sphincter
}

\author{
SATISH RATTAN, MARCIO A.F. DE GODOY, and CHIRAG A. PATEL \\ Department of Medicine, Division of Gastroenterology and Hepatology, Jefferson \\ Medical College, Thomas Jefferson University, Philadelphia, PA.
}

Short Title: RHO KINASE AND SMOOTH MUSCLE TONE

Grant Support: The work was supported by National Institutes of Diabetes and Digestive and Kidney Diseases Grant DK-35385 and an institutional grant from Thomas Jefferson University.

\begin{abstract}
Abbreviations Used in this Paper: CPI-17, inhibitory phosphoprotein for myosin phosphatase; Gö 6850, bisindolylmaleimide I (PKC inhibitor); IAS, internal anal sphincter; IASP, internal anal sphincter pressure; L-NNA, $\mathrm{N}^{\omega}$-nitro-L-arginine (NOS inhibitor); MLC, myosin light chain; MLCK, MLC kinase; MLCP, MLC-phosphatase; MSBP, mean systolic blood pressure; NANC, nonadrenergic noncholinergic; NCM, nitrocellulose membrane; NOS, nitric oxide synthase; PDE, phosphodiesterase; PKC, protein kinase $\mathrm{C} ;\left[\left(\mathrm{Ca}^{2+}\right)\right]_{i}$, free intracellular $\mathrm{Ca}^{2+}$; ROK, Rho kinase; ROCK-II or ROK $\alpha$, (primary isoform of Rho kinase involved in the smooth muscle contraction); RSM, rectal smooth muscle; RT-PCR, reverse transcription-polymerase chain reaction; SMC, smooth muscle cells; TTX, tetrodotoxin; WB, Western blot; Y 27632, (R)-(+)trans-N-(4-pyridyl)-4-(1-aminoethyl)-cyclohexanecarboxamide, (specific inhibitor of Rho kinase)
\end{abstract}

Corresponding Authors: Dr. Satish Rattan, Professor of Medicine; 901 College, Department of Medicine, Division of Gastroenterology \& Hepatology, 1025 Walnut Street, Philadelphia, PA 19107; Tel \# (215) 955-5614; Fax \# (215) 923-7697 


\section{ABSTRACT}

Background \& Aims: An increase in Rho kinase (ROK) activity has been associated with the agonist-induced sustained contraction of the smooth muscle, but its role in the pathophysiology of spontaneously tonic smooth muscle is not known. Methods: Present studies examined the effects of ROK inhibitor Y 27632 in the tonic smooth muscle of the rat internal anal sphincter (IAS) vs. in the flanking phasic smooth muscle of the rectum (RSM). In addition, studies were performed to determine the relationship between the decreases in the basal IAS tone vs. the ROK activity. Confocal microscopic studies determined the cellular distribution of smooth muscle predominant isoform of ROK (ROCK-II) in the smooth muscle cells (SMC). Results: In in vitro studies using neurohumoral inhibitors and tetrodotoxin, and the use of SMC demonstrate direct relaxation of the IAS SMC by Y 27632. The ROK inhibitor was more potent in the IAS than the RSM. The IAS relaxation by Y 27632 correlated specifically with the decrease in ROK activity. Confocal microscopy revealed high levels of ROCK-II towards the periphery of the IAS SMC. In in vivo studies, the lower doses of Y 27632 caused a potent and selective fall in the IAS pressures (IASP) without any adverse cardiovascular systemic effects. The ROK inhibitor also caused potent relaxation of the hypertensive IAS. Conclusions: 1). RhoA/ROK play a crucial role in the maintenance of the basal tone in the IAS; and 2). ROK inhibitors have a therapeutic potential in the IAS dysfunction characterized by the hypertensive IAS.

Key Words: Smooth muscle tone; basal tone; phasic contraction; Rho kinase inhibitor; RhoA/ROK 


\section{INTRODUCTION}

Disorders of the IAS underlie many clinical abnormalities, including fecal incontinence, ${ }^{1}$ and constipation. ${ }^{2}$ Specifically, hypertensive IAS is associated with a number of gastrointestinal disorders such as Hirschsprung's disease, ${ }^{3-5}$ recurrent anal fissures and hemorrhoids. ${ }^{6,7}$ Knowledge of the molecular mechanisms that underlie control of the IAS smooth muscle tone is essential to advance an understanding of the pathophysiology of these abnormalities and their therapeutic management.

The IAS tone is largely maintained by the unique properties of the smooth muscle (SM) proper. $^{5,8}$ It has been suggested that the basal tone in other sphincteric smooth muscle may be governed by $\mathrm{Ca}^{2+} / \mathrm{MLCK}$ or PKC pathways. ${ }^{9-11}$ Recently, it has been recognized that the smooth muscle contraction in response to certain agonists occurs in two phases, an initial (phasic) and a later sustained (tonic). $\mathrm{Ca}^{2+} / \mathrm{MLCK}$ is critical in the initial phase while RhoA/ROK plays a major role in the sustained contraction. ${ }^{10,12,13}$

To date, a number of approaches have been suggested to treat rectoanal motility disorders involving hypertensive IAS and incomplete relaxation. These are: $\mathrm{Ca}^{2+}$ channel blockers, ${ }^{14} \mathrm{NO}$ donors, ${ }^{15,16}$ botulinum toxin, ${ }^{17,18}$ and specific phosphodiesterase (PDE) inhibitors such as Viagra. ${ }^{19,20}$ However, these approaches may lead to variable outcomes, prominent side effects (especially cardiovascular hypotension), and desensitization. In addition, these approaches may exert their final effects via other intracellular signal transduction pathways. For example, The PDE inhibitors prevent the breakdown of $\mathrm{CGMP}^{21}$ which in turn works via the inactivation of RhoA/ROK. ${ }^{22}$

The defecation reflex (anorectal inhibitory reflex) is mediated via the sacral nerves that impinge on the local myenteric nonadrenergic noncholinergic (NANC) inhibitory neurons 
(containing neuronal nitric oxide synthase or nNOS) within the IAS. ${ }^{4,5,23}$ The loss of such neurons, ${ }^{4,24-26}$ may be associated with the hypertensive IAS and incomplete relaxation of the IAS. Therefore, the agents that bypass the NOS/cGMP pathway, work directly in the SMC, and have fewer systemic side effects, will be most desirable for the hypertensive IAS-associated motility dysfunctions.

The purpose of the present investigation therefore, is to determine the role of RhoA/ROK as the molecular bases for the genesis of basal tone in the IAS, and to explore ROK inhibitors as therapeutic potentials for the hypertensive IAS. Y 27632 has been recognized to be a selective ROK inhibitor both in vitro and in vivo settings. ${ }^{27}$

\section{MATERIALS AND METHODS}

\section{Materials and methods}

Measurement of Isometric Tension. Sprague-Dawley rats $(300-350$ g) were killed by decapitation, and the anal canal with an adjacent region of the rectum was quickly removed and transferred to oxygenated $\left(\begin{array}{lllll}95 \% & \mathrm{O}_{2} / 5 \% & \mathrm{CO}_{2}\end{array}\right)$ Krebs physiological solution (KPS) of the following composition (mM): $118.07 \mathrm{NaCl}, 4.69 \mathrm{KCl}, 2.52 \mathrm{CaCl}_{2}, 1.16 \mathrm{MgSO}_{4}, 1.01 \mathrm{NaH}_{2} \mathrm{PO}_{4}$, $25 \mathrm{NaHCO}_{3}$, and 11.10 glucose $\left(37^{\circ} \mathrm{C}\right)$. Circular smooth muscle strips $(\sim 0.5 \mathrm{X} 7 \mathrm{~mm})$ of the IAS and the rectal smooth muscle (RSM) were prepared as explained previously ${ }^{28}$ and transferred to 2-ml muscle baths containing oxygenated KPS at $37^{\circ} \mathrm{C}$. Isometric tension was measured via force transducers (model FT03; Grass Instruments, Quincy, MA) using the PowerLab/8SP dataacquisition system (AD Instruments, Australia) using Chart 5 (AD Instruments). ${ }^{29-31}$ The changes in basal IAS tone were expressed as \% of maximal relaxation by $10 \mathrm{mM}$ EDTA at the end of each experiment. ${ }^{32}$ 
The experimental protocol of the study was approved by the institutional Animal Care and Use Committee of Thomas Jefferson University and was in accordance with the recommendations of the American Association for the Accreditation of Laboratory Animal Care.

\section{Recording of Intraluminal Pressures of the IAS (IASP) and Mean Systolic Blood Pressure}

(MSBP). The high pressure zone of the IAS was identified using slow station pull through, and IASP were monitored by the modified approach of Terauchi et al., ${ }^{33}$ using solid-state catheter assembly (Millar Instruments, Houston, TX). For some studies, IASP were also monitored using custom-designed water-perfused catheter assembly (Arndorfer Inc., Greendale, WI) that consists of $25 \mathrm{~cm}$ long vinyl tube of three channels of a $0.3-\mathrm{mm}$ inside and $0.6-\mathrm{mm}$ outside diameter each.

MSBP was recorded via a non-invasive blood pressure measurement system (by tail cuff method) using computerized PowerLab/8SP data-acquisition system (AD Instruments).

Drug Responses. Concentration-response Curves (CRCs) for Y $27632(1 \mathrm{nM}$ to $100 \mu \mathrm{M})$ in the IAS and RSM were obtained in a cumulative fashion. $\mathrm{N}^{\omega}$-nitro-L-arginine (L-NNA) $(300 \mu \mathrm{M})$, neurotoxin tetrodotoxin (TTX) $(1 \mu \mathrm{M})$, propranolol $(1 \mu \mathrm{M})$, and hexamethonium $(100 \mu \mathrm{M})$ were added in the muscle bath as single doses 15 min before testing the effect of Y 27632. For in vivo studies the effects of Y 27632 on IASP and MSPB were determined in doses ranging from 0.1 to $200 \mathrm{nmols} / \mathrm{kg}$.

Preparation of Dispersed IAS Smooth Muscle Cells (SMC) and Measurement of Cell Lengths. SMC were isolated from rat IAS and RSM by sequential enzymatic digestion, filtration 
and centrifugation as described previously. ${ }^{30}$ Briefly, the smooth muscle tissues were cut into $0.2 \times 0.2 \mathrm{~mm}$ blocks and incubated in KPS containing $0.1 \%$ collagenase and $0.01 \%$ trypsin inhibitor. The partly digested strips were washed, and muscle cells were allowed to disperse spontaneously for $30 \mathrm{~min}$. SMC were then harvested by filtration through $500 \mu \mathrm{M}$ Nitex mesh and centrifuged twice at $350 \mathrm{~g}$ for $10 \mathrm{~min} .10^{4}$ cells in $100 \mu \mathrm{L}$ KPS were treated with $20 \mu \mathrm{L}$ of a solution containing the test agents. The reaction was interrupted at 5 min by the addition of 0.1 $\mathrm{ml}$ acrolein at a final concentration of $1 \%$. Individual cell length was measured by computerized image microscopy. The average length of cells in the control state or after addition of test agents was obtained from 50 cells encountered randomly in successive microscopic fields.

Rho kinase (ROK) and PKC Activity Assays. While monitoring the isometric tension, the rat RSM and IAS smooth muscle strips were quick-frozen in the basal state, and following the pretreatments with $\mathrm{Y} 27632$ and Gö 6850. The tissues were put into liquid $\mathrm{N}_{2}$ immediately and stored at $-80^{\circ} \mathrm{C}$. Later, the respective tissues were cut into small pieces and homogenized in homogenization buffer (in a volume equal to 5 times the weight). The composition of the homogenization buffer was: $50 \mathrm{mM}$ Tris-HCl, $\mathrm{pH}$ 7.5; 5 mM EDTA; $10 \mathrm{mM}$ EGTA; $1 \mathrm{mM}$ phenylmethylsulfonyl fluoride; $10 \mathrm{mM}$ benzamide; $0.3 \% \mathrm{w} / \mathrm{v} 2$ 2-mercaptoethanol). The homogenates were centrifuged $(14,000 \mathrm{rpm})$ for $5 \mathrm{~min}$ and supernatants were collected. Protein concentration in resultant supernatants was determined by the method of Lowry et al., ${ }^{34}$ using bovine serum albumin (BSA) as a standard (Pierce). $25 \mu \mathrm{g}$ of proteins in $10 \mu \mathrm{l}$ of lysate were used for kinase assay.

For the ROK activity assay, tissue lysates were mixed with $30 \mu \mathrm{M}$ Long S6 kinase substrate peptide (Upstate, Lake Placid, NY). Kinase assays were initiated by the addition of $10 \mu \mathrm{Ci}$ of $[\gamma$ - 
$\left.{ }^{32} \mathrm{P}\right]$ ATP $(3000 \mathrm{Ci} / \mathrm{mmol}$ ) (Amersham Biosciences Corp, Piscataway, NJ) and $100 \mu \mathrm{M}$ ATP, followed by incubation for $10 \mathrm{~min}$ at $30^{\circ} \mathrm{C}$. $\quad\left[{ }^{32} \mathrm{P}\right]$ substrate peptide was absorbed onto P81 Whatman phosphocellulose discs (Fisher), and free radioactivity was removed by repeated washings with $75 \mathrm{mM}$ phosphoric acid. The amount of radioactivity on the discs was measured by liquid scintillation. The results were expressed as CPM/min/mg protein. ${ }^{12,22}$

PKC activity was determined using the PKC assay kit (Upstate, Lake Placid, NY). Briefly tissue lysates were mixed with $80 \mu \mathrm{M}$ PKC substrate peptide [QKRPSQRSKYL] (Upstate), 0.1 $\mathrm{mg} / \mathrm{ml}$ phosphatidyl serine and $0.01 \mathrm{mg} / \mathrm{ml}$ diacylglycerol. Kinase assays were initiated by the addition of $10 \mathrm{uCi}$ of $\left[-{ }^{32} \mathrm{P}\right] \mathrm{ATP}(3000 \mathrm{Ci} / \mathrm{mmol})$ (Amersham) and $100 \mathrm{uM} \mathrm{ATP}$, followed by incubation for $10 \mathrm{~min}$ at $30^{\circ} \mathrm{C}$. $\left[{ }^{32} \mathrm{P}\right]$ substrate peptide radioactivity was determined as explained above. The results were expressed as percentage of the basal activity in the IAS. ${ }^{12}$

\section{Western Blot Analysis of ROCK-II, and Measurement of Free Intracellular $\mathrm{Ca}^{2+}\left[\mathrm{Ca}^{2+}\right]_{\mathrm{i}}$} Levels. ROCK-II is considered to be the primary isoform of ROK involved in the RhoA/ROKrelated pathway in the smooth muscle contraction. Levels of ROCK-II were determined using Western blot analysis. For this, first, tissue lysates of the IAS and RSM and protein extracts were prepared as described before. ${ }^{29-31}$ Then, $20 \mu \mathrm{g}$ of proteins were separated by $7.5 \%$ SDSPAGE and electrophoretically transferred onto a nitrocellulose membrane (NCM). The NCM was soaked overnight at $4^{\circ} \mathrm{C}$ in Tris-buffered saline with Tween (TBS-T; composed of: $20 \mathrm{mM}$ Tris pH 7.6, $137 \mathrm{mM} \mathrm{NaCl}$, and $0.1 \%$ Tween-20) containing 5\% nonfat dry milk. The NCM was then incubated with the primary antibodies diluted in TBS-T containing 1\% milk (1:1000 for ROCK-II and 1:20,000 for $\alpha$-actin) for $1 \mathrm{~h}$ at room temperature. After washing with TBS-T three times, the NCM was incubated with the horseradish peroxidase conjugated species-specific secondary antibody. The NCM was washed with TBS-T and the corresponding bands were 
visualized with enhanced chemiluminescence substrate using the SuperSignal ${ }^{\circledR}$ West Pico Chemiluminescent Substrate (Pierce, Rockford, IL) and captured on X-ray film. Bands corresponding to different proteins on X-ray films were scanned and their relative densities determined by using Image-Pro Plus 4.0 software (Media Cybernetics).

$\left[\mathrm{Ca}^{2+}\right]_{\mathrm{i}}$ levels of the IAS smooth muscle strips were measured using a JASCO calcium analyzer (model CAF-100, JASCO, Inc., Easton, MD) using Fura-2 AM (Molecular Probes, Eugene, OR) as the fluorescent indicator, following the method of Grynkiewictz et al., ${ }^{35}$ with specific modifications. ${ }^{36} \mathrm{R}_{\min }$ and $\mathrm{R}_{\max }$ were determined by treating the tissues with EGTA (3 $\mathrm{mM})$ and Triton X-100 (0.4\%), respectively, at the end of each experiment.

Confocal Microscopy. The SMC were cultured in DMEM medium with $10 \%$ fetal bovine serum, $5 \%$ penicillin-Streptomycin, $50 \mu \mathrm{g} / \mathrm{ml}$ gentamycin, and $2 \mu \mathrm{g} / \mathrm{ml} \mathrm{Amphotericin} \mathrm{B} \mathrm{on} \mathrm{Lab-}$ Tek II chamber slides (Nulge Nunc International, Naperville, IL) at $37^{\circ} \mathrm{C}$ and $5 \% \mathrm{CO}_{2}$ in an incubator with humidity. At confluence, culture medium was removed and the cells were fixed in $4 \%$ paraformaldehyde solution in DPBS at room temperature for $15 \mathrm{~min}$. SMC were washed three times with DPBS and incubated overnight at room temperature in a humid environment with 1:100 dilution of ROCK-II primary antibody (raised in rabbit) (Santa Cruz Biotechnology Inc., Santa Cruz, CA) in DPBS containing 0.2\% Triton X-100 and 0.5\% BSA. SMC were washed three times with DPBS and incubated with Texas red-conjugated anti-rabbit secondary antibody (1:200) (Santa Cruz) and FITC-conjugated $\alpha$-actin antibody (1:800) (Sigma) in DPBS with $0.3 \%$ Triton X-100 and 2\% Donkey serum for $1 \mathrm{hr}$. SMC were then washed three times with DPBS and chambers were removed from slides. The slides were air-dried and coverslips were mounted on the slides using VECTASHIELD mounting medium (Vector Labs, 
Burlingame, CA). Florescence was analyzed with Bio-Rad MRC 600 laser scanning confocal microscope (Zeiss Anxiovert 100, Overkochen, Germany). Texas Red was excited at $543 \mathrm{~nm}$ with helium/neon laser and FITC was excited at $488 \mathrm{~nm}$ with argon laser. The fluorophores were detected separately and overlay images were generated automatically by the imaging software.

Data Analysis. Data are presented as means \pm standard error for the number of animals indicated. Western blot data were normalized to smooth muscle $\alpha$-actin (relative density). When comparing two groups, an unpaired Student's t test was used. CRCs were analyzed using two way ANOVA test.

Drugs and Chemicals. Y 27632 was purchased from Calbiochem (San Diego, CA). ROCK-II antibody was purchased from Santa Cruz biotechnology Inc. (Santa Cruz, CA). $\alpha$-actin antibody, L-NNA, tetrodotoxin (TTX), propranolol, and hexamethonium chloride were obtained from sigma (St. Louis, MO). Gö 6850 (bisindolylmaleimide I) was obtained from Tocris (Ellisville, MO). L-NNA, TTX, propranolol, and hexamethonium chloride were dissolved in distilled water.

\section{RESULTS}

Effect of Y 27632 on the Basal Tone of the IAS vs. the Phasic Activity of the Rectal Smooth Muscle (RSM). The ROK inhibitor caused a concentration-dependent fall in the basal tone of the IAS (Figure 1) with $\sim 30$ fold higher potency than in the phasic smooth muscle of the RSM. $\mathrm{EC}_{50}$ in causing the fall in the IAS tone vs. in the phasic activity of the RSM were $0.44 \mu \mathrm{M}$ and 
$13 \mu \mathrm{M}$, respectively. Y $27632(1 \mu \mathrm{M})$ caused 50\% inhibition $\left(\mathrm{IC}_{50}\right)$ in the basal IAS tone without a significant effect in the RSM. Typical tracings of the effects of Y 27632 in the IAS and RSM are shown in Figure 2, panels A and B, respectively.

Effect of Y 27632 on Internal Anal Sphincter Pressure (IASP) and Mean Systolic Blood Pressure (MSBP). Similar to the fall in the basal IAS tone in in vitro studies, the ROK inhibitor also caused fall in the IASP in a dose-dependent manner (Figure 3). In this regard, 1 and 10 $\mathrm{nmol} / \mathrm{kg}$ caused $37.5 \pm 5.2 \%$ and $71.0 \pm 7.7 \%$ fall in the IASP, respectively. Similar doses of the inhibitor caused a minimal fall in the MSBP of $0.8 \pm 0.6 \%$ and $11.4 \pm 4.7 \%$, respectively. Y 27632 was 200 times more potent in causing a fall in the IASP as compared to the fall in the MSBP.

Influence of Neurotoxin Tetrodotoxin (TTX) and Neurohumoral Inhibitors on Y 27632Induced Fall in the Basal IAS Tone. TTX $(1 \mu \mathrm{M})$, hexamethonium $(100 \mu \mathrm{M})$, and $\beta$ adrenoceptor blocker propranolol $(1 \mu \mathrm{M})$ had no significant effect on Y 27632-induced fall in the basal IAS tone $(\mathrm{p}>0.05 ; \mathrm{n}=5-7$; Figure $4 \mathrm{~A})$. Consistent with these data, the fall in the IAS tone by the ROK inhibitor was also not modified by the NOS inhibitor L-NNA (300 $\mu \mathrm{M})(\mathrm{p}>$ $0.05 ; \mathrm{n}=5-7)$. These data suggest that $\mathrm{Y} 27632$ causes a fall in the IAS tone by its effect directly at the SMC.

Effect of Y 27632 on the Isolated Smooth Muscle Cells (SMC) of the IAS vs. the RSM.

Direct effect of the ROK inhibitor on the IAS SMC was confirmed by the concentrationdependent relaxation of the SMC isolated from the IAS (Figure 4B). In this regard, $10 \mu \mathrm{M} \mathrm{Y}$ 
27632 caused maximal relaxation $(37.8 \pm 4.4 \%)$ of the IAS SMC, and had no significant effect on the lengths of SMC from the RSM ( $n=4$ animals). Not shown data similar to the effect of $Y$ 27632 was obtained with another ROK inhibitor H 1152 in the IAS smooth muscle and the SMC.

\section{Comparison of ROK activity in the IAS vs. RSM in the Basal State and Following Y 27632.}

Actual levels of ROK activity were found to be significantly higher in the IAS vs. RSM (*; p < $0.05 ; \mathrm{n}=4$; Figure $5 \mathrm{~A}$ ). There was a close relationship between the fall in the IAS tone and the decrease in ROK activity in the presence of different concentrations of $\mathrm{Y} 27632$ (1nM to $10 \mu \mathrm{M})$ (Figure $5 \mathrm{~B})\left(\mathrm{r}^{2}=0.95\right) .1 \mu \mathrm{M}$ of $\mathrm{Y} 27632$ caused $50.1 \pm 3.3$ and $45.8 \pm 2.2 \%$ decrease in the IAS tone and in the ROK activity, respectively. On the contrary, $1 \mu \mathrm{M}$ Gö 6850 (PKC inhibitor) caused no significant change in the basal ROK activity in the IAS $(97.4 \pm 7 \%$ vs. $100 \%$ of the basal state) $(\mathrm{p}>0.05 ; \mathrm{n}=4)$. These data provide further evidence in favor of role of RhoA/ROK in the basal tone in the IAS.

Western blot analysis of ROCK-II revealed significantly higher levels of ROCK-II in the IAS as compared with the RSM (*; $p<0.05 ; \mathrm{n}=4$; Fig. 5C).

The fall in the IAS tone following the ROK inhibitor was not related to either the changes in $\left[\mathrm{Ca}^{2+}\right]_{\mathrm{i}}$ or the PKC activity $(\mathrm{p}>0.05 ; \mathrm{n}=4$; Figure 6$)$.

Presence of ROCK-II in the SMC of the IAS. To determine the cellular localization of ROCK-II, we performed confocal microscopy studies. The data revealed significantly higher levels of RhoA and ROCK-II towards the periphery of the IAS SMC as compared to those of the RSM (data is shown only with ROCK-II in the IAS SMC; Figure 7). Data further show that the ROK inhibitor caused the redistribution of ROCK-II to the inside of the cells. These data 
suggest that in the basal state, $\mathrm{RhoA} / \mathrm{ROK}$ remain in active state to maintain basal tone in the IAS.

Effect of Rho Kinase Inhibitor in the Hypertensive IAS. In order to determine the clinical relevance of RhoA/ROK and the inhibitor, we investigated the effect of Y 27632 in the hypertensive IAS. For this, we used the rat model of IAS in the presence of NOS inhibitor LNNA $(300 \mu \mathrm{M})$. This treatment mimicked the symptoms of segmental Hirschsprung's disease, elevated IAS tone and incomplete IAS relaxation. ${ }^{5}$ In these experiments, L-NNA increased the IAS tone from $0.7 \pm 0.07 \mathrm{~g}$ to $1.2 \pm 0.08 \mathrm{~g}(\mathrm{n}=5)$, and nearly obliterated the NANC relaxation. In the hypertensive IAS Y 27632 caused a concentration-dependent fall in the IAS tone (Figure 8), and this fall was significantly greater with $3 \times 10^{-7}$ and $1 \times 10^{-6} \mathrm{M}(* ; \mathrm{p}<0.05 ; \mathrm{n}=5)$. Data suggest the potential use of ROK inhibitors in the hypertensive IAS. Not shown, similar data were obtained in in vivo studies.

\section{DISCUSSION}

The studies show that the basal tone in the IAS is critically dependent on RhoA/ROK. Selectivity and potency of the ROK inhibition in causing IAS relaxation without significant side effects, and its effectiveness in the hypertensive IAS suggest a therapeutic potential of this approach in certain conditions associated with the hypertensive IAS.

The relaxant effect of ROK inhibition works directly at the SMC due to the lack of effect of different neurohumoral inhibitors and the neurotoxin TTX, and by the demonstration of the effects in the SMC. It is well known that NO is the major inhibitory mediator of the IAS 
relaxation in response to NANC nerve stimulation. ${ }^{5,23,28,37}$ However, RhoA/ROK-mediated smooth muscle relaxation of the IAS is independent of the NOS pathway since the NOS inhibitor L-NNA failed to modify this effect.

RhoA/ROK are known to be present throughout the SMC, and during the sustained phase of the contraction they translocate to the periphery of the SMC for the ROK activation. ${ }^{38,39}$ Once activated, ROK inhibits MLC-phosphatase (MLCP) either directly or via phosphorylation of CPI-17 (P-CPI-17). ROK-mediated MLCP inhibition decreases dephosphorylation of phosphorylated-MLC $\mathrm{ML}_{20}\left(\mathrm{P}-\mathrm{MLC}_{20}\right)$ and is responsible for the maintenance of sustained contraction of the smooth muscle. This information from the existing literature only comes from studies that use various agonists to induce smooth muscle contraction. This concept has never been tested in the spontaneously tonic smooth muscles (such as the IAS).

Present studies show that the IAS relaxation as a result of ROK inhibition by Y 27632 is selective and several fold potent as compared with the RSM. There is a direct relationship between the changes in the IAS tone and ROK activity. In addition, the PKC inhibitor Gö 6850 does not modify the basal activity of ROK in the IAS. The presence of higher levels of RhoA/ROK in the periphery of the IAS SMC (in contrast to the RSM SMC) was demonstrated by actual ROK activity, and by direct visualization of ROCK-II via confocal microscopy. ROCK-II is also present in higher levels in the IAS than in the RSM at the translational levels as shown by Western blot analysis (Figure 5C). Data suggest that RhoA/ROK translocation is highly selective and is characteristic of the IAS SMC in the basal state. In addition, our preliminary studies suggest that pretreatment of the IAS SMC with constitutively active RhoA mutant $\left(\mathrm{RhoA}^{\mathrm{V} 14}\right)^{22}$ causes an increase in the ROK activity and shortening of the SMC (data not shown). The ROK inhibitor was found to be selective in its mechanism of action since it does 
not affect the basal levels of $\left[\mathrm{Ca}^{2+}\right]_{i}$ and PKC activity.

Taken together, the data suggest that RhoA/ROK play a critical role in the maintenance of basal tone in the IAS. Increase in the $\left[\mathrm{Ca}^{2+}\right]_{\mathrm{i}}$ and MLCK activity may be important in the initial (phasic) contraction of smooth muscle rather than in the maintenance of tone. PKC has been speculated to play a role in the tonic contraction of certain smooth muscles, ${ }^{10,13}$ however its exact role in the basal tone of the IAS is not known. A part of PKC-mediated effect is dependent on MLCP inhibition via P-CPI-17, which also is one of the mechanisms of action of RhoA/ROK as stated above. ${ }^{39}$ Whether or not there is any overlap between these events is not known.

RhoA/ROK have been suggested to play an important role in the etiology and in the therapy of cardiovascular hypertension. ${ }^{40}$ The role of RhoA/ROK upregulation in the hypertensive IAS or in the hypermotility of other gastrointestinal smooth muscles has not been investigated. A hypertensive IAS accompanied by inadequate relaxation is a prominent pathophysiological finding of Hirschsprung's disease, hemorrhoids and anal fissures. ${ }^{5,15,41}$

The therapeutic potential of ROK inhibitor in the IAS dysfunction associated with the hypertensive IAS is important from two standpoints. Firstly, as shown by the present data, such agents cause IAS relaxation independent of the NOS/cGMP pathway since relaxation still remains intact in the presence of NOS inhibition. It is thought that one of the underlying causes of the sphincteric smooth muscle hypertension may be the lack of NOS-containing myenteric inhibitory neurons. ${ }^{3,26,33,42}$ Consequently, an agent that causes relaxation via NOS pathway is less likely to succeed in treating the IAS dysfunction. Secondly, other smooth muscle relaxants may cause undesirable cardiovascular hypotension. Present studies further demonstrate that the doses of ROK inhibitor causing near maximal fall in the IASP have no significant effect on the cardiovascular system. 
Inhibitors of PDE5 (that selectively inhibit cGMP PDE) such as sildenafil (Viagra) have been studied for the symptomatic relief of these conditions with variable results and undesirable side effects. $^{19,43}$ The successful effect of the PDE inhibitors relies on the inhibition of cGMP breakdown causing an increase in the cGMP levels. ${ }^{43}$ According to recent studies, the effect of cGMP, in turn, depends on ROK inactivation. ${ }^{22,44}$ ROK inhibitors (that cause direct and potent relaxation of the smooth muscle) may have wide therapeutic implications in the hypermotility of the gastrointestinal tract.

To examine the clinical relevance of ROK inhibition, we used a hypertensive IAS model characterized by an increase in the IAS tone and incomplete NANC relaxation similar to the Hirschsprung's disease in humans. ${ }^{5,37,45}$ We determined that Y 27632 causes potent relaxation in this model. Therefore, the present studies may have clinical utility in treatment of anorectal motility disorders characterized by the hypertensive IAS.

From the data we conclude the basal tone in the IAS and perhaps other smooth muscle sphincters is critically dependent upon RhoA/ROK. The selectivity and potency of the ROK inhibition in causing IAS relaxation (free of side effects), and its effect in the hypertensive IAS, suggest a therapeutic potential of this approach in conditions such as Hirschsprung's disease and perhaps in other spastic GI motility disorders.

\section{REFERENCES}

1. Schiller LR. Fecal incontinence. In: Feldman M, ed. Sleisenger \& Fordrtran's Gastrointestinal and Liver Disease. 7 ed. Philadelphia, PA: W.B. Saunders Co., 2002:164-174.

2. Lennard-Jones JE. Constipation. In: Feldman M, ed. Sleisenger \& Fordtan's Gastrointestinal and Liver Disease. 7 ed. Philadelphia, PA: W.B. Saunders Co., 2002:181-210. 
3. O'Kelly TJ, Davies JR, Tam PK, Brading AF , Mortensen NJMC. Abnormalities of nitric-oxideproducing neurons in Hirschsprung's disease: Morphology and implications. J Ped Surg 1994;29:294-300.

4. Vanderwinden J-M, De Laet M-H, Schiffmann SN, Mailleux P, Lowenstein CJ, Snyder SH, Vanderhaeghen J-J. Nitric oxide synthase distribution in the enteric nervous system of Hirschsprung's disease. Gastroenterology 1993;105:969-973.

5. Rattan S. The internal anal sphincter: regulation of smooth muscle tone and relaxation. Neurogastroenterol Motil 2005;17:50-59.

6. McCallion K, Gardiner KR. Progress in the understanding and treatment of chronic anal fissure. Postgrad Med J 2002;77:753-758.

7. Madoff RD, Fleshman JW. American gastroenterological association technical review on the diagnosis and treatment of hemorrhoids. Gastroenterology 2004;126:1463-1473.

8. Culver PJ, Rattan S. Genesis of anal canal pressures in the opossum. Am J Physiol Gastrointest Liver Physiol 1986;251:G765-G771.

9. Harnett KM, Biancani P. Calcium-dependent and calcium-independent contractions in smooth muscles. Am J Med 2003;115:24S-30S.

10. Harnett KM, Cao W, Biancani P. Signal-transduction pathways that regulate smooth muscle function. Signal transduction in phasic (esophageal) and tonic (gastroesophageal sphincter) smooth muscles. Am J Physiol Gastrointest Liver Physiol 2005;288:G407-G416.

11. Cao W, Sohn UD, Bitar KN, Biancani P, Harnett KM. MAPK mediates PKC-dependent contractions of cat esophageal and lower esophageal sphincter circular smooth muscle. Am $\mathbf{J}$ Physiol Gastrointest Liver Physiol 2003;285:G86-G95.

12. Murthy KS, Zhou H, Grider JR, Brautigan DL, Eto M, Makhlouf GM. Differential signalling by muscarinic receptors in smooth muscle: m2-mediated inactivation of myosin light chain kinase via $\mathrm{G}_{\mathrm{i} 3}, \mathrm{Cdc} 42 / \mathrm{Rac} 1$ and p21-activated kinase 1 pathway, and m3-mediated $\mathrm{MLC}_{20}(20 \mathrm{kDa}$ regulatory 
light chain myosin II) phosphorylation via Rho-associated kinase/myosin phosphatase targeting subunit and protein kinase C/CPI-17 pathway. Biochem J 2003;374:145-155.

13. Murthy KS, Grider JR, Kuemmerle JF, Makhlouf GM. Sustained muscle contraction induced by agonists, growth factors, and $\mathrm{Ca}^{2+}$ mediated by distinct PKC isozymes. Am J Physiol Gastrointest Liver Physiol 2000;279:G201-G210.

14. Knight JS, Birks M, Farouk R. Topical diltiazem ointment in the treatment of chronic anal fissure. Br J Surg 2001;88:453-456.

15. Jones OM, Brading AF, Mortensen NJ. The physiology, pharmacology, and therapeutic manipulation of the internal anal sphincter. Can J Gastroenterol 2002;16:249-257.

16. Altmore DF, Rinaldi M, Miltito G. Glyceryl trinitrate for chronic anal fissure-healing or headache. Dis Colon Rectum 2000;43:174-181.

17. Maria G, Brisinda G, Bentivoglio AR, Cassetta E, Gui D, Albanese A. Botulinum toxin injections in the internal anal sphincter for the treatment of chronic anal fissure: long-term results after two different dosage regimens. Ann Surg 1998;228:664-669.

18. Hoogerwerf WA, Pasricha PJ. Botulinum toxin for spastic gastrointestinal disorders. Baillières Best Pract Res Clin Gastroenterol 1999;13:131-143.

19. Torrabadella L, Salgado G, Burns RW, Berman IR. Manometric study of topical sildenafil (Viagra) in patients with chronic anal fissure: sildenafil reduces anal resting tone. Dis Colon Rectum 2004;47:733-738.

20. Milone M, BiBaise JD. A pilot study of the effects of sildenafil on stool characteristics, colon transit, anal sphincter function, and rectal sensation in healthy men. Dig Dis Sci 2005;50:10051011.

21. Manallack DT, Hughes RA, Thompson PE. The next generation of phosphodiesterase inhibitors: structural clues to ligand and substance selectivity of phosphodiesterases. J Med Chem 2005;48:3449-3462. 
22. Murthy KS, Zhou H, Grider JR, Makhlouf GM. Inhibition of sustained smooth muscle contraction by PKA and PKG preferentially mediated by phosphorylation of rhoA. Am J Physiol Gastrointest Liver Physiol 2003;284:G1006-G1016.

23. Rattan S, Sarkar A, Chakder S. Nitric oxide pathway in rectoanal inhibitory reflex of opossum internal anal sphincter. Gastroenterology 1992;103:43-50.

24. Goyal RK, Hirano I. The enteric nervous system. N Engl J Med 1996;334:1106-1115.

25. Goyal RK. Targets of enteric motor neurones: smooth muscle cells. Gut 2000;47 (suppl IV):iv38iv39.

26. Takahashi T. Pathophysiological significance of neuronal nitric oxide synthase in the gastrointestinal tract. J Gastroenterol 2003;38:421-430.

27. Ishizaki T, Uehata M, Tamechika I, Keel J, Nonomura K, Maekawa M. Pharmacological properties of Y-27632, a specific inhibitor of rho-associated kinases. Mol Pharmacol 2000;57:976-983.

28. Rattan S, Chakder S. Role of nitric oxide as a mediator of internal anal sphincter relaxation. Am J Physiol Gastrointest Liver Physiol 1992;262:G107-G112.

29. Rattan S, Al Haj R, De Godoy MAF. Mechanism of internal anal sphincter relaxation by CORM-1, authentic CO, and NANC nerve stimulation. Am J Physiol Gastrointest Liver Physiol 2004;287:G605-G611.

30. De Godoy MAF, Rattan S. Autocrine regulation of internal anal sphincter tone by renin-angiotensin system: comparison with phasic smooth muscle. Am J Physiol Gastrointest Liver Physiol 2005;289:G1164-G1175.

31. Rattan S, Regan RF, Patel CA, De Godoy MAF. Nitric oxide not carbon monoxide mediates nonadrenergic noncholinergic relaxation in the murine internal anal sphincter. Gastroenterology 2005;129:1954-1966.

32. Biancani P, Walsh JH, Behar J. Vasoactive intestinal polypeptide: a neurotransmitter for relaxation of the rabbit internal anal sphincter. Gastroenterology 1985;89:867-874. 
33. Terauchi A, Kobayashi D, Mashimo H. Distinct roles of constitutive nitric oxide synthases and interstitial cells of Cajal in rectoanal relaxation. Am J Physiol Gastrointest Liver Physiol 2005;289:G291-G299.

34. Lowry OH, Rosebrough NJ, Farr AL, Randall RJ. Protein measurement with the Folin phenol reagent. J Biol Chem 1951;193:265-275.

35. Grynkiewictz G, Poenie M, Tsien RY. A new generation of $\mathrm{Ca}^{2+}$ indicators with greatly improved fluorescence properties. J Biol Chem 1985;260:3440-3450.

36. Chakder S, Sarma D, Rattan S. Mechanism of internal anal sphincter smooth muscle relaxation by phorbol 12,13-dibutyrate. Am J Physiol Gastrointest Liver Physiol 2001;280:G1341-G1350.

37. O'Kelly T, Brading A, Mortensen N. Nerve mediated relaxation of the human internal anal sphincter: The role of nitric oxide. Gut 1993;34:689-693.

38. Somlyo AP, Somlyo AV. $\mathrm{Ca}^{2+}$ sensitivity of smooth muscle and nonmuscle myosin II: modulated by G proteins, kinases, and myosin phosphatase. Physiol Rev 2003;83:1325-1358.

39. Ito M, Nakano T, Erdodi F, Hartshorne DJ. Myosin phosphatase: structure, regulation and function. Mol Cell Biochem 2004;259:197-209.

40. Budzyn K, Marley PD, Sobey CG. Targeting Rho and Rho-kinase in the treatment of cardiovascular disease. Trends Pharmacol Sci 2006;27:97-104.

41. Cook TA, Brading AF, Mortensen NJ. The pharmacology of the internal anal sphincter and new treatments of ano-rectal disorders. Aliment Pharmacol Ther 2001;15:887-898.

42. Sivarao DV, Mashimo H, Thatte HS, Goyal RK. Lower esophageal sphincter is achalasic in nNOS and hypotensive in $\mathrm{WW}^{\mathrm{v}}$ mutant mice. Gastroenterology 2001;121:34-42.

43. Seftel AD. Phosphodiesterase type 5 inhibitors: molecular pharmacology and interactions with other phosphodiesterases. Curr Pharm Des 2005;1:4047-4058.

44. Murthy KS. Signaling for contraction and relaxation in smooth muscle of the gut. Annu.Rev.Physiol 2005. 
45. Chakder S, McHugh KM, Rattan S. Inhibitory neurotransmission in lethal spotted mutant mice: A model for Hirschsprung's disease. Gastroenterology 1997;112:1575-1585.

\section{FIGURE LEGENDS}

Figure 1. Effect of Y 27632 in the internal anal sphincter (IAS) vs. the rectal smooth muscle (RSM). Considering the $\mathrm{EC}_{50}$ values, Rho kinase inhibitor was 30 times more potent in the IAS vs. $\operatorname{RSM}(* ; \mathrm{p}<0.05 ; \mathrm{n}=5)$.

Figure 2, $\mathbf{A}$ and B, typical tracings of the effect of Y 27632 in the IAS and RSM, respectively. The ROK inhibitor causes concentration-dependent fall in the IAS tone and phasic contractions of the RSM. However, the ROK inhibitor was several fold more sensitive in the IAS vs. the RSM.

Figure 3. In in vivo studies to show that the in the lower dose range Y 27632 causes significant fall in the intraluminal pressures in the IAS (IASP) $(* ; p<0.05 ; n=4)$ without significant effect on the mean systolic blood pressure (MSBP). Considering the $\mathrm{EC}_{50}$ values, Y 27632 was 200 times more potent in causing fall in the IASP vs. the MSBP. Maximal fall in the IASP was in reference to the pressures in the rectum. Conversely, maximal fall in MSBP was in reference to a possible fall of $60 \mathrm{mmHg}$; in the data shown, $200 \mathrm{nmol} / \mathrm{kg}$ of Y 27632 caused a fall of $\sim 30$ $\mathrm{mmHg}$.

Figure 4. A. The neurohumoral inhibitors including the NOS inhibitor L-NNA have no significant effect on the IAS relaxation caused by the ROK inhibitor $(p>0.05 ; n=5-7)$. B. The ROK inhibitor causes concentration-dependent and significant relaxation of the SMC from the IAS (*; $p<0.05 ; \mathrm{n}=4$ ) but no significant effect in the RSM SMC. Percent increase in the cell length (in the presence of different concentrations of Y 27632) of the spontaneously contracted SMC was calculated on the bases of original cell length. As pointed out in Methods section, in 
each case average length of cells was obtained from 50 cells in a random manner.

Figure 5. A. Comparison of ROK activity in the IAS vs. RSM reveals higher levels of the activity in the IAS $(* ; p<0.05 ; n=4)$. B. Relationship between the decrease in the IAS tone and in the ROK activity following different concentrations of ROK inhibitor. The comparison reveals significant correlation between the two events $\left(r^{2}=0.95\right)$. C. Western blot analysis demonstrates higher levels of ROCK-II protein expression in the IAS vs. the RSM $(* ; \mathrm{p}<0.05 ; \mathrm{n}$ $=4)$.

Figure 6. Effect of Y $27632(10 \mu \mathrm{M})$ on free intracellular $\mathrm{Ca}^{2+}$ levels and PKC activity in the IAS. Data shows that the ROK inhibitor has no significant effect on the levels of $\left[\mathrm{Ca}^{2+}\right]_{i}$ and PKC activity ( $\mathrm{p}>0.05 ; \mathrm{n}=4)$.

Figure 7. Confocal microscopy showing the immunocytochemical localization of ROCK-II in the SMC of the IAS. Data show higher levels of ROCK-II towards the periphery of the SMC isolated from the IAS in the basal state (upper right panel). Pretreatment of the IAS SMC with Y 27632 causes redistribution of ROCK-II and relaxation of the SMC (lower right panel).

Figure 8. Effect of Y 27632 on the basal tone in the control and hypertensive IAS. The ROK inhibitor causes relaxation of the IAS, and that in the submaximal concentrations, it causes significantly higher relaxation in the hypertensive IAS (*; $\mathrm{p}<0.05 ; \mathrm{n}=5)$. 


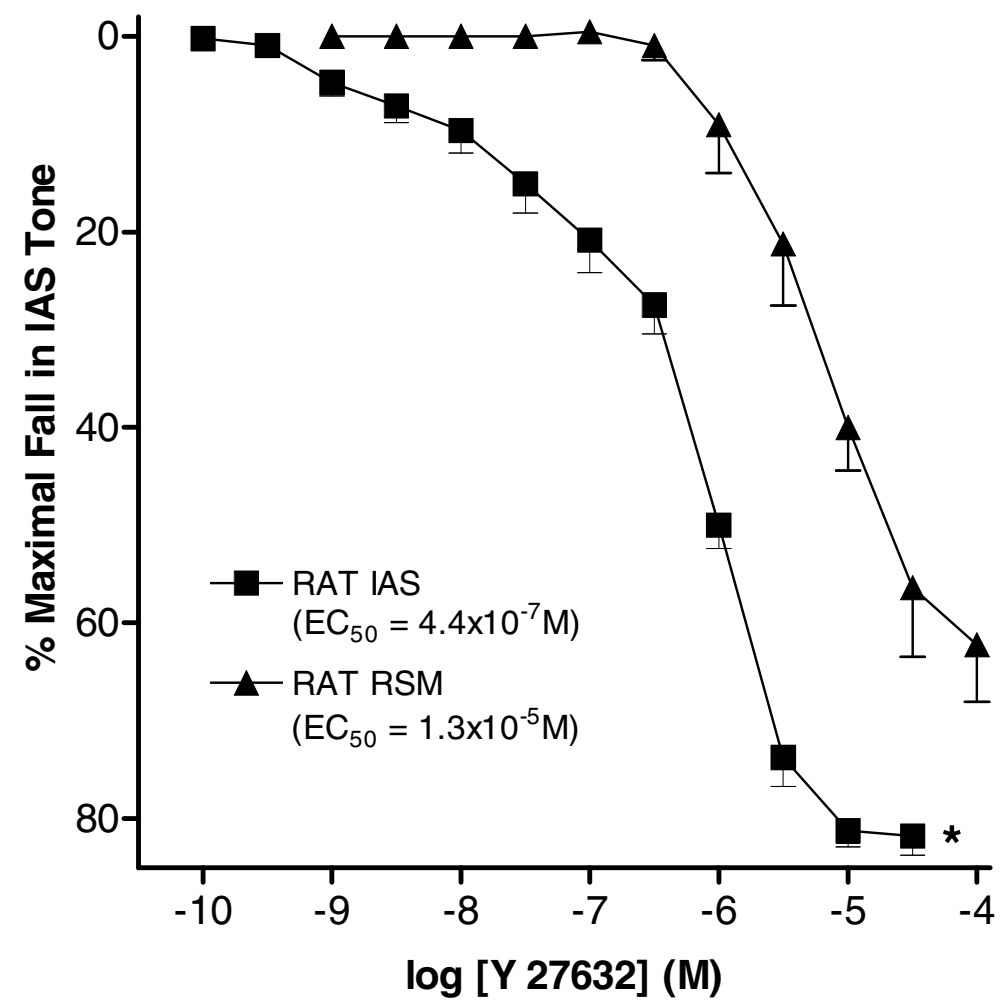

Figure 1. 

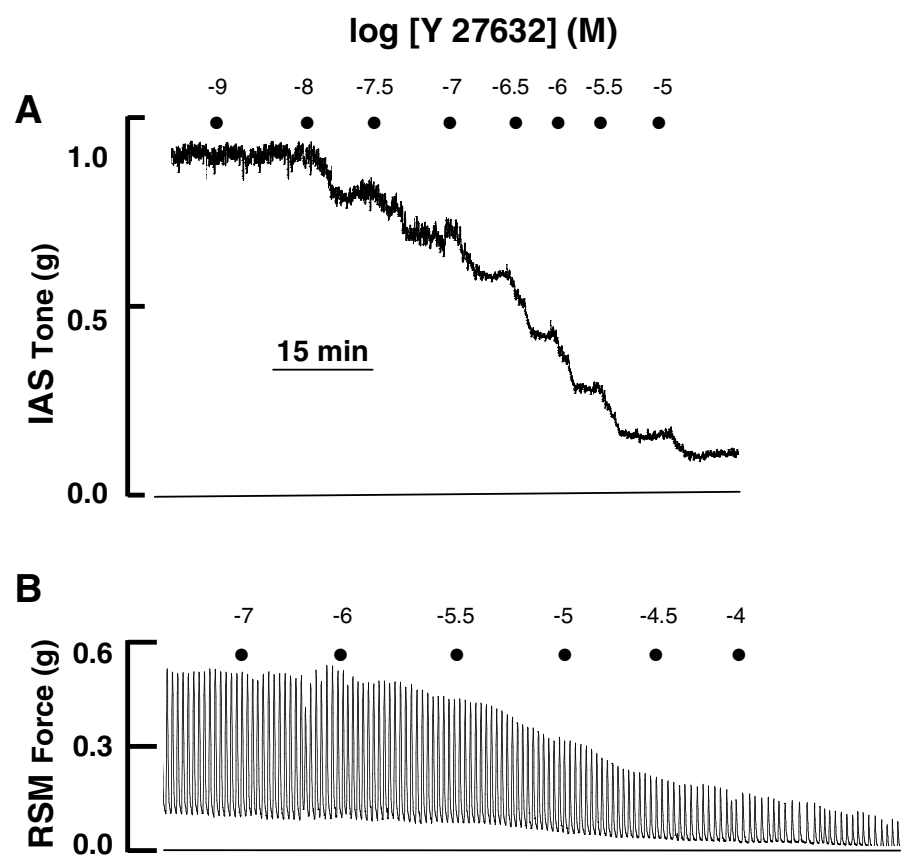

Figure 2.

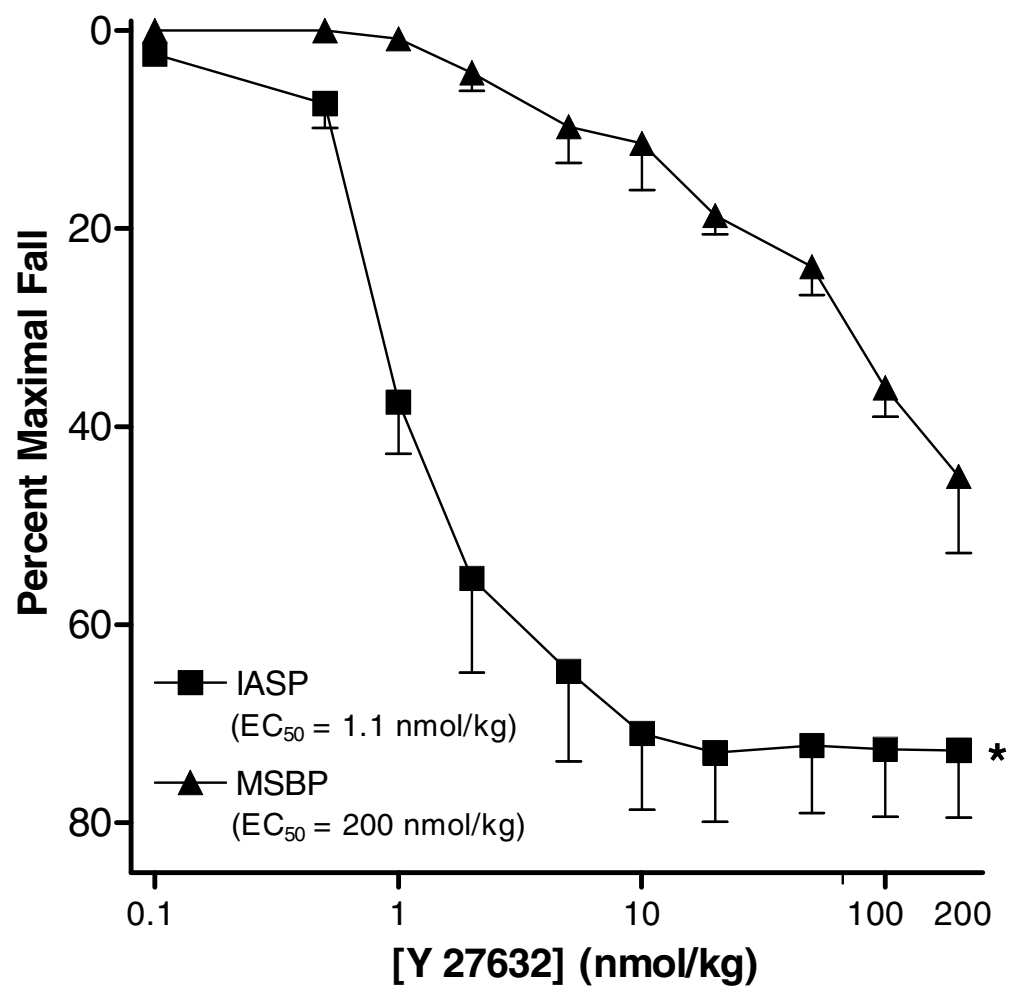

Figure 3. 

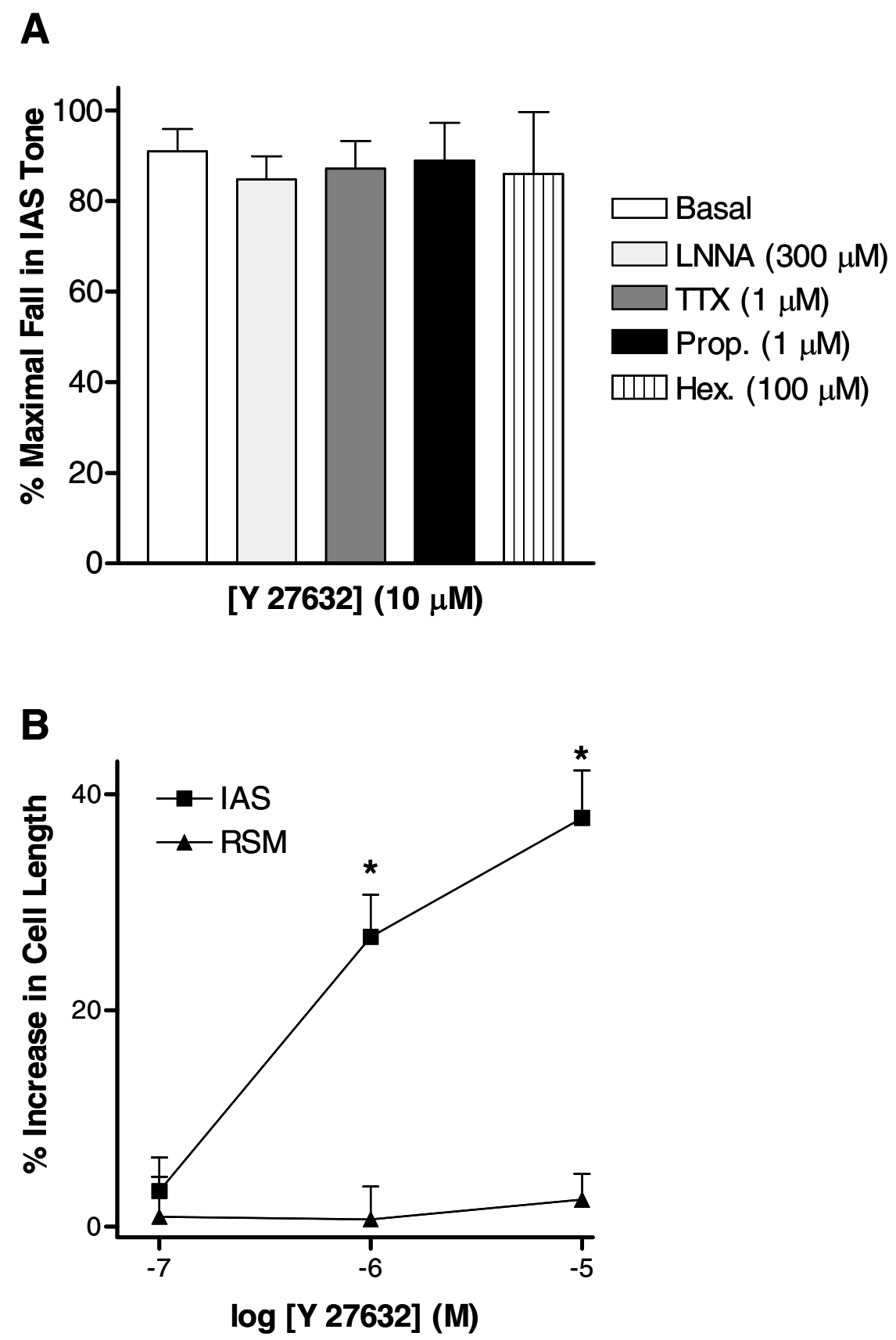

Figure 4. 
C

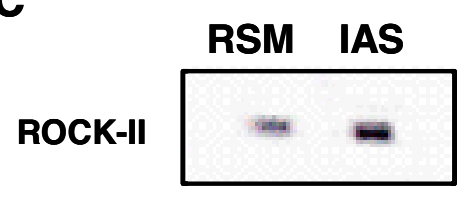

A
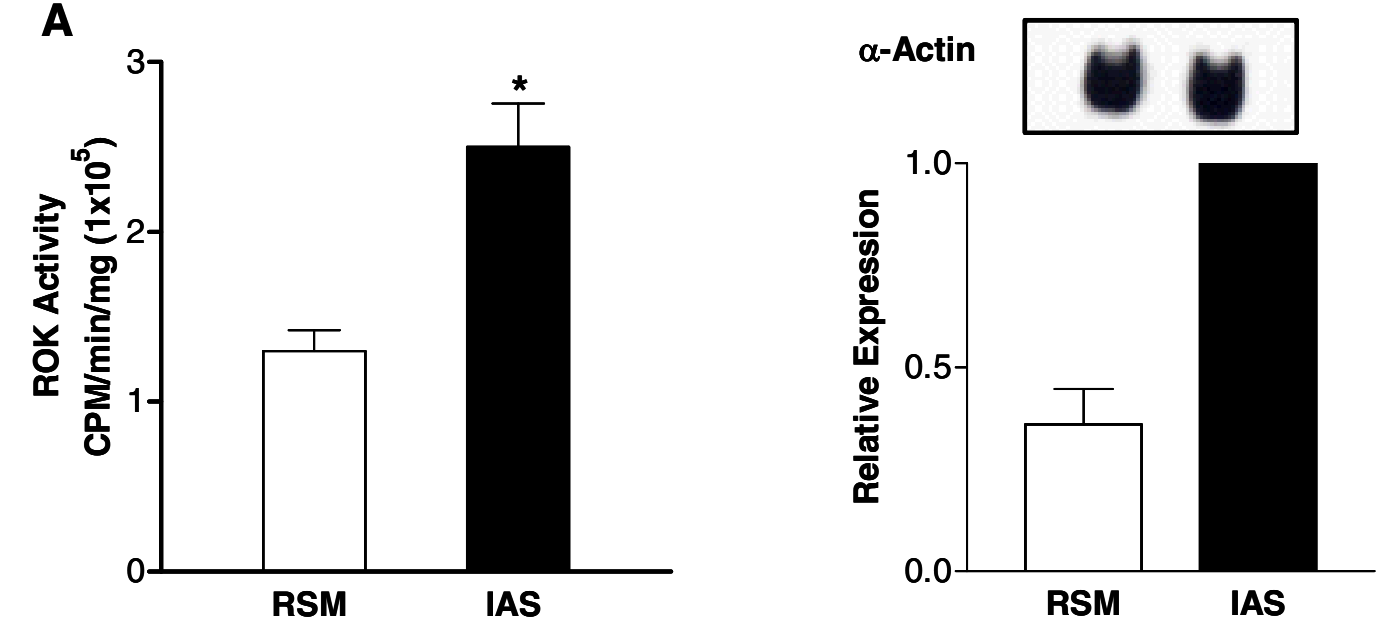

B

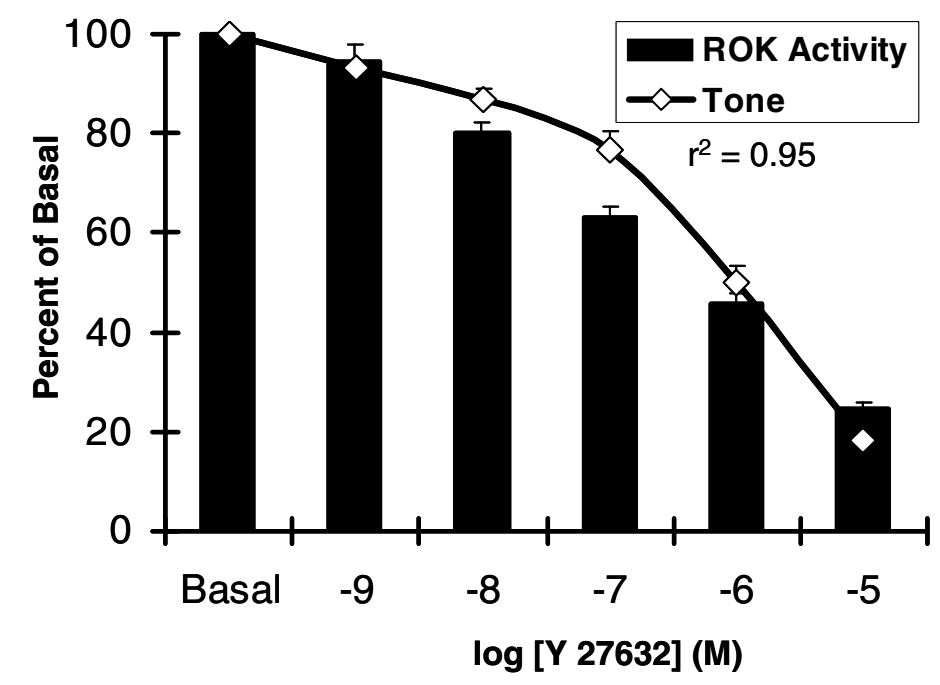

Figure 5. 


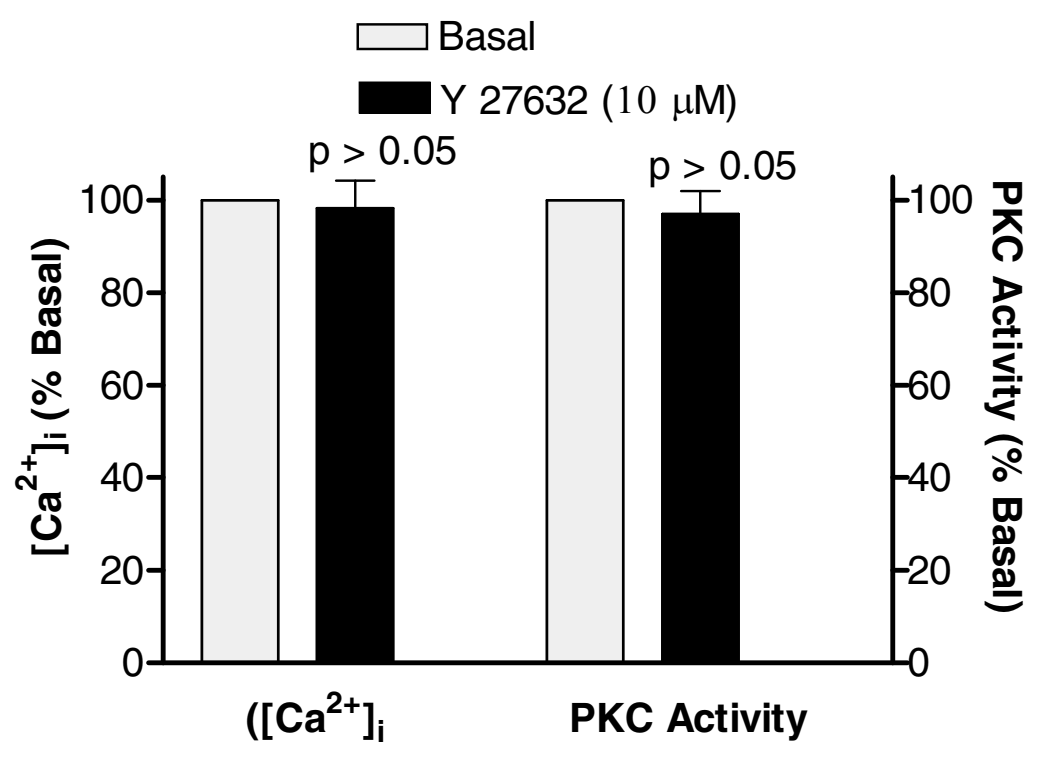

Figure 6.

\section{IAS SMC}

$\alpha$-actin

ROCK-II

Basal
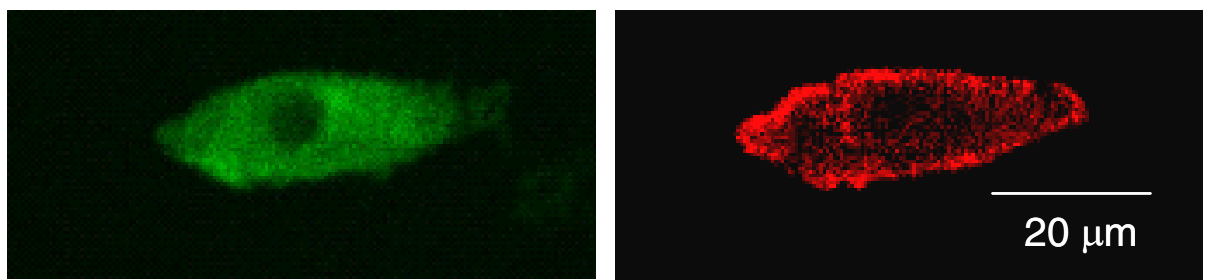

$\mathrm{Y} 27632(10 \mu \mathrm{M})$
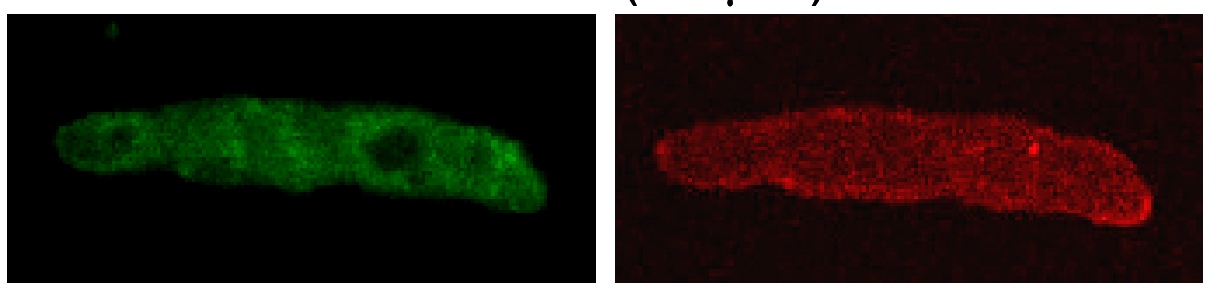

Figure 7. 


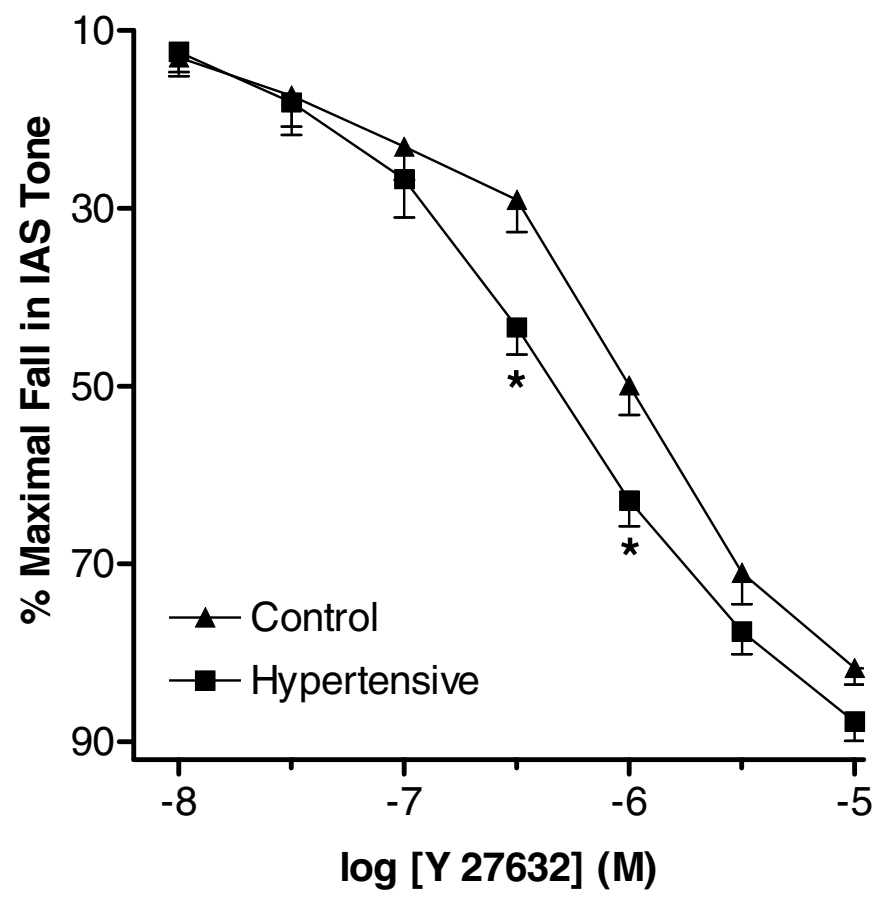

Figure 8. 